\title{
CT assessment of the correlation between clinical examination, panoramic radiography and bone involvement in oral malignant tumours
}

\author{
Altaf Hussain Chalkoo', ${ }^{1}$ ibhuti Kaul ${ }^{2, *}$, Rudra Kaul $^{3}$, Mohsin Muzaffar Tak ${ }^{4}$, Sanjeet Singh Risam ${ }^{5}$ \\ ${ }^{1}$ Professor \& HOD, ${ }^{2}$ Registrar, ${ }^{3}$ Lecturer, ${ }^{4}$ Assistant Professor, ${ }^{5}$ B-grade Specialist, ${ }^{\mathbf{1}, 2,4}$ Dept. of Oral Medicine \& Radiology, \\ ${ }^{3}$ Dept. of Conservative Dentistry and Endodontics, ${ }^{\mathbf{1}, \mathbf{4}}$ Govt. Dental College \& Hospital, Srinagar, Jammu \& Kashmir, ${ }^{\mathbf{2}, \mathbf{3}}$ Indira \\ Gandhi Govt. Dental College \& Hospital, Jammu, ${ }^{5}$ Dept. of Health, Jammu \& Kashmir Government, Jammu \& Kashmir, India
}

*Corresponding Author:

Email: kaulvibhuti@yahoo.com

\begin{abstract}
Introduction and Objectives: Oral cancer is a dreadful disease occurring most commonly in the Indian subcontinent. Since there is rarely a second chance for cure, initial approach to treatment is important. A crucial factor in pretreatment assessment of these patients is determination of presence and extent of bone invasion.

Materials and Methods: A descriptive study was carried out on 25 patients with clinically and histopathologically diagnosed squamous cell carcinoma. Clinical examination, OPG and contrast enhanced CT was carried out on all patients. Bone adjacent to the tumor was assessed on the CT and served as a gold standard. The other two modalities were then compared to the gold standard.

Results: The sensitivity and specificity for clinical examination and OPG were $63.2 \%$ \& $66.7 \%$ and $78.9 \%$ and $83.3 \%$ respectively. The positive predictive value and negative predictive value for clinical examination were $85.7 \%$ and $36.4 \%$ respectively. The positive predictive value and negative predictive value for OPG were $93.7 \%$ and $55.5 \%$ respectively.

Conclusion: The present study showed that careful clinical examination followed by OPG may serve as a preliminary evaluation to detect probable presence and extent of bone invasion in oral malignancies.
\end{abstract}

Keywords: Bone invasion, conventional CT, Orthopantomograph, Squamous cell carcinoma.

\section{Introduction}

These days the world is heading towards various types of non-communicable diseases, which are also known as modern epidemics. Among these modern epidemics, cancer is one of the commonest cause of mortality in developed countries. Cancer, which is defined as an abnormal growth of cells, can affect any tissue or organ of the body.

Oral squamous cell carcinoma (OSCC) constitutes a major health problem worldwide, leading to one of the 10 most common causes of death. Oral cancer represents approximately $13 \%$ of all cancers, thereby, translating into 30,000 new cases every year. ${ }^{1}$ According to the World Health Organization, carcinoma of the oral cavity is the sixth commonest cancer in males and tenth commonest cancer in females in developing countries ${ }^{2}$ and constitutes $12 \%$ of all cancers in men and $8 \%$ of all cancers among women. ${ }^{3}$

It is the most prevalent cancer related to the consumption of tobacco, alcohol and other carcinogenic products. ${ }^{4}$ It is estimated that more than 1 million new oral cancer cases are being detected annually in the Indian subcontinent of which $92-95 \%$ are Oral squamous cell carcinoma (OSCC), ${ }^{5}$ accounting for 50$70 \%$ of the total cancer mortality. ${ }^{6}$

There is rarely a second chance for cure. Therefore, the initial approach to therapy is critical. Depending on the site and extent of the primary tumor and the status of the lymph nodes, the treatment of oral cancer may be by surgery alone, radiation therapy alone, chemotherapy alone or a combination of these.
Diagnostic imaging has potential impact on the detection, diagnosis, preoperative evaluation, staging and postoperative follow-up of cancer patients.

Several imaging modalities such as conventional radiography, ultrasonography, computed tomography, bone scanning and magnetic resonance imaging have been used to investigate the presence of bone involvement by oral cancers. ${ }^{7-9}$ All these methods seem to have specific limitations; however, the use of computed tomography (CT) in the preoperative assessment of malignant tumors seems to be the most valuable technique, because it shows soft and bone tissues in the same exam and has a high sensitivity and specificity for assessment of bone destruction. ${ }^{10,11}$

The burden of cancer is still increasing worldwide despite advances in diagnosis and treatment. Bone invasion alters the clinical staging and management of oral carcinoma on the assumption that resection of bone invaded by tumour can result in disease progression and poor outcome. The assessment of presence and extent of bone invasion is an important part of the preoperative staging of oral carcinoma to help in better treatment planning and determination of prognosis of these patients.

With this factor in mind, this study was undertaken to evaluate clinical examination and orthopantomography in predicting bone invasion using computed tomography in oral malignant tumours. 


\section{Materials and Methods}

This descriptive study was carried out in the Department of Oral Medicine and Radiology, Government Dental College, Srinagar. Ethical committee clearance was obtained prior to the commencement of the study.

The study consisted of 25 patients ( 16 males and 9 females) clinically and histopathologically diagnosed as oral malignancies seen at our clinic from November 2012 to December 2014. Patient age ranged from 26 to 80 years (mean 53.7 years).

\section{Inclusion Criteria}

25 patients with histopathologically diagnosed oral malignancy approximating the bone were included in the study.

\section{Exclusion Criteria}

1. Claustrophobic patients

2. Pregnant patients

3. Patients with recurrence of carcinoma after radiotherapy and chemotherapy

4. Patients allergic to the dye

5. Medically compromised patients

6. Lesions which were clinically suspicious but histopathologically negative for malignancy.

All patients fulfilling the above criteria were informed about the study being conducted and informed consent was obtained from them. After a detailed case history, all patients were subjected to complete clinical examination. In order to detect bone invasion by malignant tumours upon clinical examination, the main clinical parameters used were inspection, palpation, and description of lesions. Stage assessment was made according to the criteria of the $6^{\text {th }}$ edition TNM staging system established by the American Joint Committee on Cancer. ${ }^{12}$

Subsequently, the patients were subjected to OPG and CT examination.

Panoramic radiographs were taken on Orthophos (Sirona, Germany) extraoral machine.

CT scans were performed on Somatom Definition AS, 64 slice helical CT scanner (Siemens Medical Systems, Germany) with a slice thickness of $0.6 \mathrm{~mm}$ in axial section. Scans were performed after the intravenous (IV) administration of iodine non-ionic contrast (Iopamiro 370, Bracco, Patheon Italia S.p.A., FR, Italy) (Fig. 3) that was infused immediately before starting scanning. The CT images were considered the golden standard in our study.

The radiographic images were assessed by a medical and a maxillofacial radiologist independently. Any differences were resolved by consensus. An example of case is illustrated in Fig. 1-4.

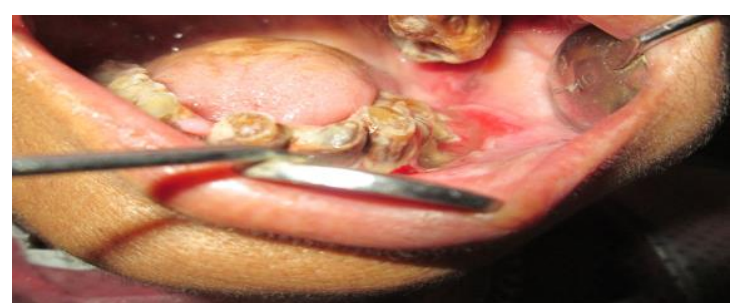

Fig. 1: Clinical examination showing infiltrative ulcer mandibular left gingivobuccal sulcus

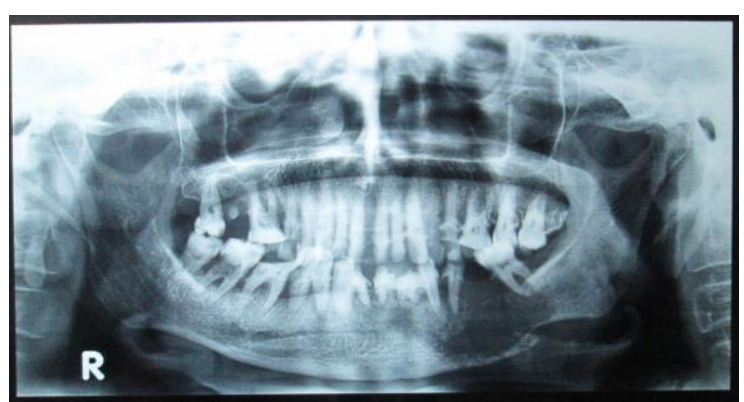

Fig. 2: Orthopantomograph of the patient

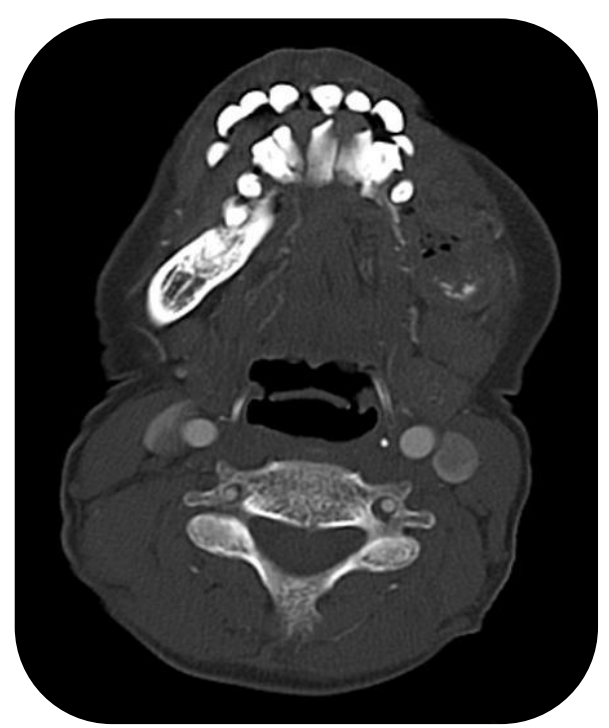

Fig. 3: Contrast-enhanced Computed Tomography (Bone Window) 


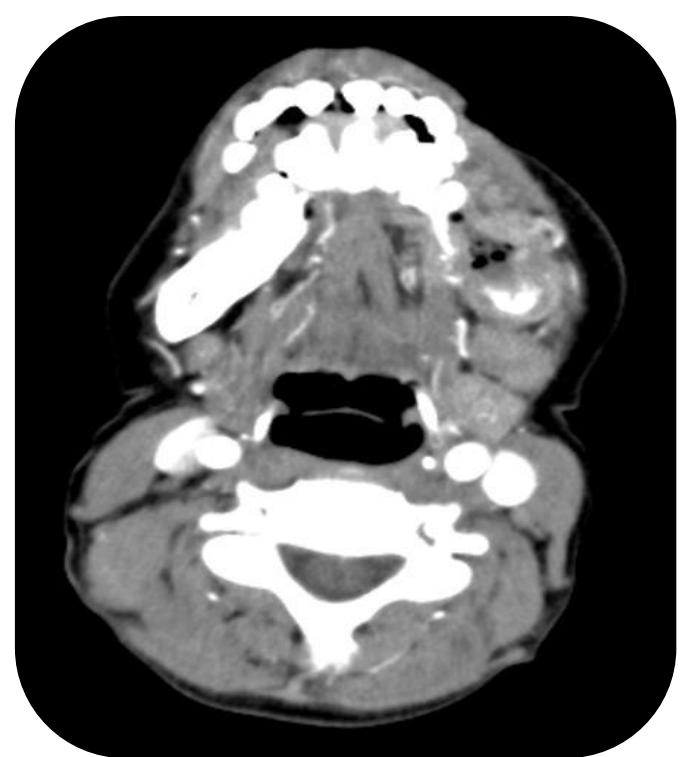

Fig. 4: Contrast-enhanced Computed Tomography (Soft-tissue Window)

\section{Criteria for bone invasion in CT}

In $\mathrm{CT}$ bone invasion is suggestive when tumour tissue was visible outside the cortical bone and the cortical bone was seen to be partially eroded or destroyed.

\section{Diagnostic tests done for the study}

Sensitivity: Ability of a test to identify correctly all those who have the disease. [True positives]

Sensitivity: true positive/ [true positive + false negative] x 100

Specificity: Ability of a test to identify correctly those who do not have the disease. [True negatives]

Specificity: true negative/ [true negative + false positive] x 100

Positive predictive value: Means that a patient with a positive test result has in fact the disease in question.

Positive predictive value: true positive/ [true positive + false positive]

Negative predictive value: Means that a patient with a negative test result has in fact no disease in question.

Negative predictive value: true negative/ [true negative + false negative]

\section{Results}

A descriptive study was carried out on 25 patients who were histopathologically diagnosed as oral malignancy. Patient age ranged from 26 to 80 years. Among 25 subjects, 16 were males and 9 were females. The mean age of the patients was $53.72 \pm 14.458$ years. The mean age of male and female patients was $52.06 \pm 14.158 \& 56.67 \pm 15.362$ respectively.

Two reviewers, one general and one maxillofacial radiologist, retrospectively assessed the radiographic images independently. There was complete agreement between the 2 observers, with the exception of 2 patients $(\kappa=0.80)$.

Out of 25 patients who were clinically and histopathologically diagnosed as oral malignancy, CT detected bone invasion in 19 cases and 6 cases showed absence of bone invasion. CT was considered as gold standard in this study.

Correlation of morphology of lesions with bone invasion are shown in table 1, graph 1. Correlation of Stage with bone invasion are depicted in table 2, graph 2. Sensitivity, Specificity, positive and negative predictive values of Clinical Examination are shown in table 3.

Results of OPG in comparison to the gold standard are depicted in table 4 . Table 5 depictes the Sensitivity, Specificity, positive and negative predictive values of OPG. Wilcoxon signed rank test was used to determine the difference between the clinical and CT and OPG and CT examinations. [Table 6]

Table 1: Correlation of morphology of lesions with bone invasion

\begin{tabular}{|l|c|c|c|c|c|}
\hline \multirow{2}{*}{ Morphology } & \multicolumn{4}{|c|}{ CT Scan } & \multirow{2}{*}{ Total } \\
\cline { 2 - 5 } & \multicolumn{2}{|c|}{ Present } & \multicolumn{2}{|c|}{ Absent } & \\
\cline { 2 - 5 } & No. & \%age & No. & \%age & \\
\hline $\begin{array}{l}\text { Papillary } \\
\text { Ulcer }\end{array}$ & 6 & 31.6 & 1 & 16.7 & 7 \\
\hline $\begin{array}{l}\text { Infiltrative } \\
\text { Ulcer }\end{array}$ & 9 & 47.4 & 3 & 50.0 & 12 \\
\hline Nodular & 4 & 21.0 & 2 & 33.3 & 6 \\
\hline Total & 19 & 100 & 6 & 100 & 25 \\
\hline
\end{tabular}

Graph 1: Morphology vs CT Scan

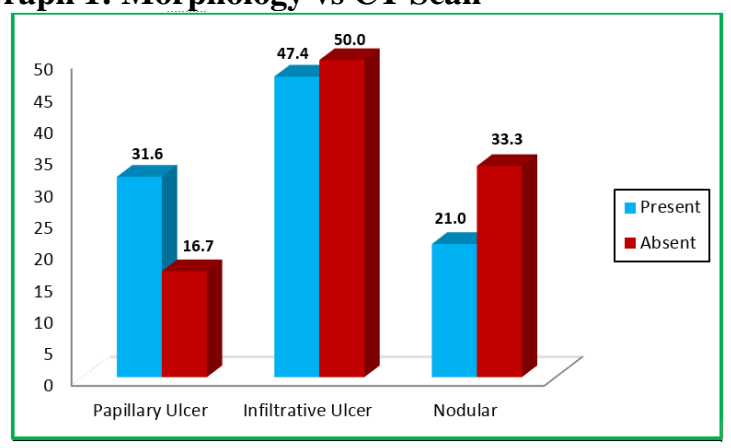

Table 2: Correlation of Stage with bone invasion

\begin{tabular}{|l|c|c|c|c|c|}
\hline \multirow{3}{*}{ Stage } & \multicolumn{4}{|c|}{ CT Scan } & \multirow{2}{*}{ Total } \\
\cline { 2 - 5 } & \multicolumn{2}{|c|}{ Present } & \multicolumn{2}{c|}{ Absent } & \\
\cline { 2 - 5 } & No. & \%age & No. & \%age & \\
\hline I & 1 & 5.3 & 2 & 33.3 & 3 \\
\hline II & 5 & 26.3 & 2 & 33.3 & 7 \\
\hline III & 8 & 42.1 & 2 & 33.3 & 10 \\
\hline IVA & 3 & 15.8 & 0 & 0 & 3 \\
\hline IVB & 2 & 10.5 & 0 & 0 & 2 \\
\hline Total & 19 & 100 & 6 & 100 & 25 \\
\hline
\end{tabular}




\section{Graph 2: Stage vs CT Scan}

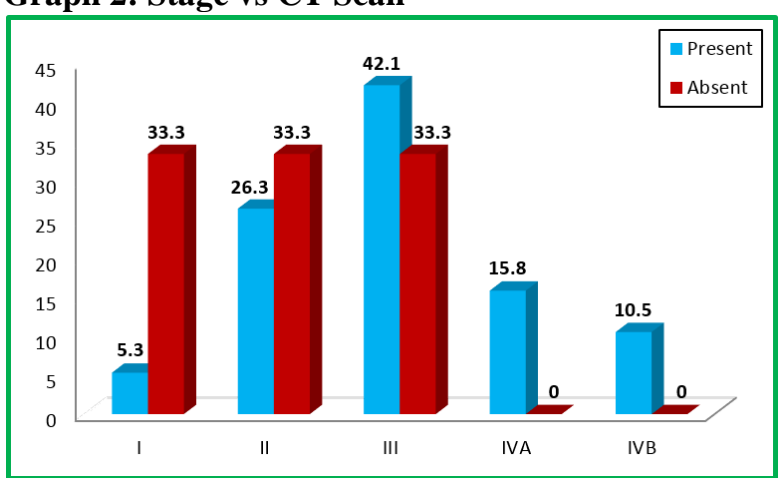

Table 3: Sensitivity, Specificity, positive and negative predictive values of Clinical Examination

\begin{tabular}{|l|c|c|}
\hline \multicolumn{1}{|c|}{ Variable } & Value & $\begin{array}{c}\text { 95\% Confidence } \\
\text { Interval }\end{array}$ \\
\hline Sensitivity & $63.2 \%$ & $(38.36 \%$ to $83.72 \%)$ \\
\hline Specificity & $66.7 \%$ & $(22.27 \%$ to $95.67 \%)$ \\
\hline $\begin{array}{l}\text { Positive } \\
\text { Predictive Value }\end{array}$ & $85.7 \%$ & $(57.17 \%$ to $98.22 \%)$ \\
\hline $\begin{array}{l}\text { Negative } \\
\text { Predictive Value }\end{array}$ & $36.4 \%$ & $(10.92 \%$ to $69.19 \%)$ \\
\hline
\end{tabular}

Table 4: Results of OPG in comparison to the gold standard

\begin{tabular}{|l|c|c|c|}
\hline \multirow{2}{*}{ OPG } & \multicolumn{2}{c|}{ CT Scan } & \multirow{2}{*}{ Total } \\
\cline { 2 - 3 } & Positive & Negative & \\
\hline Positive & $\mathrm{TP}=15$ & $\mathrm{FP}=1$ & 16 \\
\hline Negative & $\mathrm{FN}=4$ & $\mathrm{TN}=5$ & 9 \\
\hline Total & 19 & 6 & 25 \\
\hline
\end{tabular}

Table 5: Sensitivity, Specificity, positive and negative predictive values of $O P G$

\begin{tabular}{|l|c|c|}
\hline \multicolumn{1}{|c|}{ Variable } & Value & $\begin{array}{c}\text { 95\% Confidence } \\
\text { Interval }\end{array}$ \\
\hline Sensitivity & $78.9 \%$ & $(54.43 \%$ to $93.95 \%)$ \\
\hline Specificity & $83.3 \%$ & $(35.88 \%$ to $99.58 \%)$ \\
\hline $\begin{array}{l}\text { Positive } \\
\text { Predictive Value }\end{array}$ & $93.7 \%$ & $(69.79 \%$ to $99.84 \%)$ \\
\hline $\begin{array}{l}\text { Negative } \\
\text { Predictive Value }\end{array}$ & $55.5 \%$ & $(21.21 \%$ to $86.31 \%)$ \\
\hline
\end{tabular}

Table 6: Wilcoxon signed rank test was used to determine the difference between the clinical and CT and OPG and CT examinations

\begin{tabular}{|l|c|c|c|}
\hline Comparison & Z-value & P-value* & Remarks \\
\hline $\begin{array}{l}\text { CT vs } \\
\text { Clinical } \\
\text { Suspicion }\end{array}$ & -1.667 & 0.096 & $\begin{array}{c}\text { Not } \\
\text { significant }\end{array}$ \\
\hline CT vs OPG & -1.342 & 0.18 & $\begin{array}{c}\text { Not } \\
\text { significant }\end{array}$ \\
\hline
\end{tabular}

\section{Discussion}

Tumours clinically approximating the bone may not show bone invasion clinically or on plain radiography, yet such cases may show poor prognosis when tumor is excised without the bone or cases where there is no bone invasion, treatment may involve unnecessary mandibular resections.

The accurate prediction of the presence and extent of mandibular invasion takes on considerable importance as an inappropriate segmental resection will increase the complexity of reconstruction and the burden of rehabilitation. Conversely an inappropriate marginal resection will potentially compromise the oncological aims and increase the risk of local recurrence.

In order to predict invasion of the mandible several radiological techniques have been introduced over the past few years. These have included plain radiographs, ${ }^{13}$ tomography, ${ }^{8}$ radionuclide scans, ${ }^{13}$ ultrasonography, ${ }^{14}$ computerized tomography ${ }^{8,13,15}$ and magnetic resonance imaging. ${ }^{16}$

Our study was undertaken to assess the accuracy of clinical examination and OPG findings as compared to contrast enhanced CT. The use of CT in the assessment of bone invasion in oral cavity cancers has been advocated by a number of authors. ${ }^{8}$ Close et $\mathrm{al}^{15}$ endorsed $\mathrm{CT}$ as the radiologic study of choice.

The study was conducted on patients who reported to the Department of Oral Medicine and Radiology. These patients were biopsy confirmed cases of oral malignancies with probable bone involvement. Among the 25 patients included in our study, 16 patients were males and 9 patients were females with a mean age of 53.7 years (range 26-80 years). This is similar to the cohort studied by Albuquerque et $\mathrm{al}^{12}$ where the mean age of the patients was 57.8 years (range 29-84 years).

These patients were grouped according to TNM classification. There were 3 patients with T1, 7 patients with T2, 10 patients with T3 and 5 patients with T4 disease.

In all the patients, clinical and OPG examination was carried out followed by contrast enhanced CT. The CT findings were considered to be the gold standard in our study. The CT scan reported 19 out of 25 patients had tumour infiltrating the bone i.e. $76 \%$. This is in comparison to $68 \%$ rate as reported by Kalavrezos et $\mathrm{al}^{17}$ and Albuquerque et al ${ }^{18}$ in their studies.

\section{Results of clinical examination compared to the gold standard}

In our study, clinical examination showed 14 positives out of which 12 were confirmed by $\mathrm{CT}$ and 4 false positive cases, with an accuracy of $64 \%$. It showed a sensitivity of $63.2 \%$, specificity of $66.7 \%$, positive predictive value of $85.7 \%$ whereas a negative predictive value of $36.4 \%$. This is in concordance with the findings of Van Cann et $\mathrm{al}^{19}$ who found the sensitivity of clinical examination to be $59.1 \%$. In 
contrast, Close et $\mathrm{al}^{8}$ and Van den Brekel et $\mathrm{al}^{20}$ reported lower sensitivity of clinical examination at $53 \%$ and $39 \%$ respectively. Leipzig ${ }^{13}$ reported an accuracy of clinical examination to be $84 \%$ in their study.

The relationship between lesion site and presence of bone invasion has been analysed by several authors. ${ }^{21,22}$ According to these studies, tumors located in the retromolar area and alveolar ridge are those most likely to invade bone (88\%) since the soft tissue layer in these areas is quite thin, which allows rapid bone invasion by the tumour. This was confirmed in our study as well.

The morphologic aspect of the tumours associated with bone involvement has not been much studied. ${ }^{23}$ Of the 12 patients presenting lesions with clinical aspect of infiltrative ulcer, $9(75 \%)$ had bone invasion. This high propensity for bone invasion by these lesions might be due to the principal vector of growth toward the deep tissues. 6 out of $7(85.7 \%)$ papillary ulcers and 4 out of $6(66.7 \%)$ nodular lesions showed bony involvement.

The concept of association of tumour stage with mandibular bone involvement is supported by many studies. ${ }^{18,22}$ Our study echoed those findings, showing a gradual progression of $33.3 \%$ stage I patients showing bone invasion to $100 \%$ of stage IV .

\section{Results of OPG compared to the gold standard}

In our study, OPG findings showed bone invasion in 16 patients out of which 15 were confirmed on CT with one false positive case and accuracy of $80 \%$. Statistical analysis showed a sensitivity of $78.9 \%$, specificity of $83.3 \%$, positive predictive value of $93.7 \%$ whereas a negative predictive value of $55.5 \%$.

This is in concordance with the sensitivity values as reported by Smyth et $\mathrm{al}^{24}(73.6 \%)$ and Kushraj et $\mathrm{al}^{25}$ (75\%). Ord et $\mathrm{al}^{26}$ showed OPG to have a sensitivity of $86.6 \%$ and a specificity of $80 \%$. Rao et $\mathrm{al}^{27}$ reported a higher sensitivity of $92 \%$ and a specificity of $58 \%$. Leipzig ${ }^{13}$ reported accuracy of OPG to be $68 \%$ in his study.

Various authors have opined that OPG is useful when there is gross invasion of cortical bone. However, it is not useful in evaluating minimal invasion or involvement of the inner cortex. ${ }^{27}$

There were certain limitations to our study. Firstly, there was no post-operative histopathologic correlation for confirmation of bone invasion as is done by most studies. Our study was done on the lines of Albuquerque et $\mathrm{al}^{23}$ and was purely a clinico-radiologic study. Secondly, ours was a qualitative assessment of simply presence of absence of bone invasion. This is in contrast to quantitative assessment as done by few other authors. ${ }^{18,28}$ Not seeking comment on the extent of invasion was similar to Smyth et $\mathrm{al}^{24}$ as they believed it to be because of the crudeness of radiology in reflecting the histological changes. Thirdly, the sample size in study was small although exactly the same number as
Albuquerque et $\mathrm{al}^{23}$, this necessitates further study using larger cohorts in order to validate the findings.

\section{Conclusion}

The following inferences were drawn from the study:

1. The sensitivity and specificity for clinical examination were $63.2 \%$ and $66.7 \%$ respectively.

2. The sensitivity and specificity for OPG were $78.9 \%$ and $83.3 \%$ respectively.

3. The positive predictive value and negative predictive value for clinical examination were $85.7 \%$ and $36.4 \%$ respectively.

4. The positive predictive value and negative predictive value for OPG were $93.7 \%$ and $55.5 \%$ respectively.

The study concludes that detection of bone invasion by clinical examination and OPG may be subjective, but detection of bone invasion by these methods is efficient to an acceptable degree. Also, the study showed a higher propensity for stage IV lesions involving the alveolus or hard palate to show bone invasion.

This study concludes that careful clinical examination followed by OPG may serve as a preliminary evaluation to detect probable presence and extent of bone invasion in oral malignancies. However, due to smaller sample size the results obtained in this study may not be definitive.

\section{References}

1. Khandekar SP, Bagdey PS, Tiwari RR. Oral cancer and some epidemiological factors: A hospital based study. Indian J Community Med. 2006;31:157-9.

2. Mehrotra R, Yadav S. Oral squamous cell carcinoma: etiology, pathogenesis and prognostic value of genomic alterations. Indian J Cancer. 2006; 43:60-6.

3. Sankaranarayanan R. Oral cancer in India: An epidemiologic and clinical review. Oral Surg Oral Med Oral Pathol. 1990;69:325-30.

4. Khanna SS, Karjodkar FR. Circulating immune complexes and trace elements (copper, iron and selenium) as markers in oral precancer and cancer: a randomised, controlled clinical trial. Head Face Med. 2006;2:33.

5. Molly S, Rosebush, Rao KS, Sandeep S, Weikuan Gu, Charles R et al. Oral cancer: Enduring characteristics and emerging trends. J Tenn Dent Assoc 2011;91(2):24-9.

6. Park K. Textbook of Preventive and Social Medicine. 14th ed. Jabalpur: Banarsidas Bhanor Publisher;1994.p.261-5.

7. Nakayama E, Yoshiura K, Yuasa K, Tabada O, Araki K, Sanda $\mathrm{S}$ et al. Detection of bone invasion by gingival carcinoma of the mandible: a comparison of intraoral and panoramic radiography and computed tomography. Dentomaxillofac Radiol. 1999;28(6):352-6.

8. Shaha AR. Preoperative evaluation of the mandible in patients with carcinoma of the floor of the mouth. Head Neck. 1991;13(5):398-402.

9. O'Brien CJ, Carter RL, Soo KC, Barr LC, Hamlyn PJ, Shaw $\mathrm{HJ}$. Invasion of the mandible by squamous carcinomas of the oral cavity and oropharynx. Head Neck Surg. 1986;8(4):247-56.

10. Cavalcanti MGP, Ruprecht A, Quets J. Progression of maxillofacial squamous cell carcinoma evaluated using 
computer graphics and spiral computed tomography. Dentomaxillofac Radiol. 1999;28(4):238-44.

11. Huntley TA, Busmanis I, Desmond P, Wiesenfeld D. Mandibular invasion by squamous cell carcinoma: a computed tomographic and histological study. Br J Oral Maxillofac Surg. 1996;34(1):69-74.

12. American Joint Committee on Cancer (AJCC). Cancer staging manual. 6th ed. Philadelphia: Lippincott-Raven publishers; 2002.

13. Leipzig B. Assessment of mandibular invasion by carcinoma. Cancer. 1985; 56: 1201-1205.

14. Marchetta F, Sako K, Murphy J. The periosteum of the mandible and intraoral carcinoma. Am J Surg. 1971;122:711-3.

15. Close LG, Merkel M, Burns DK, Shaefer SD. Computed tomography in the assessment of mandibular invasion by intraoral carcinoma. Ann Oto Rhinol Laryngol. 1986;95:383-8.

16. Weisman R, Kimmelman C. Bone scanning in the assessment of mandibular invasion by oral cavity carcinomas. Laryngoscope. 1982;92:1-4.

17. Millesi W, Prayer L, Helmer M. Gritzmann N. Diagnostic imaging of tumor invasion of the mandible. Int J Oral Maxillofac Surg. 1990;19(5):294-8.

18. Brown JS, Griffith JF, Phelps PD Browne RMA. Comparison of different imaging modalities and direct inspection after periosteal stripping in predicting the invasion of the mandible by oral squamous cell carcinoma. Br J Oral Maxillofac Surg. 1994;32(6):347-59.

19. Van Cann EM, Koole R, Oyen WJG, de Rooy JWJ, de Wilde PC, Slootweg PJ, et al. Assessment of mandibular invasion of squamous cell carcinoma by various modes of imaging: constructing a diagnostic algorithm. Int J Oral Maxillofac Surg 2008;37:535-41.

20. van den Brekel MWM, Runne RW, Smeele LE, Tiwari RM, Snow GB, Castelijns JA. Assessment of tumour invasion into the mandible: the value of different imaging techniques. Eur Radiol. 1998;8(9):1552-7.

21. Huntley TA, Busmanis I, Desmond P, Wiesenfeld D. Mandibular invasion by squamous cell carcinoma: a computed tomographic and histological study. Br J Oral Maxillofac Surg. 1996;34(1):69-74.

22. Zupi AL, Califano, Maremonti, Longo P, Ciccarelli F, Soricelli RA. Accuracy in the diagnosis of mandibular involvement by oral cancer. J Craniomaxillofac Surg. 1996;24(5):281-4.

23. Albuquerque MAP, Kuruoshi ME, Oliveira IRS, Cavalcanti MGP. CT assessment of the correlation between clinical examination and bone involvement in oral malignant tumors. Braz Oral Res. 2009;23(2):196-202.

24. Smyth DA, O’Dwyer TP, Keane CO, Stack J. Predicting mandibular invasion in mouth cancer. Clin Otolaryngol Allied Sci. 1996;21(3):265-8.

25. Kushraj T, Chatra L, Shenai P, Rao PK. Bone invasion in oral cancer patients: A comparison between orthopantomograph, conventional computed tomography, and single positron emission computed tomography. J Cancer Res Therap. 2011;7(4):438-41.

26. Ord RA, Sarmadi M, Papadimitrou J. A comparison of segmental and marginal bony resection for oral squamous cell carcinoma involving the mandible. J Oral Maxillofac Surg. 1997;55:470-77.

27. Rao LP, Das SR, Mathews A, Naik BR, Chacko E, Pandey M. Mandibular invasion in oral squamous cell carcinoma: investigation by clinical examination and orthopantomogram. Int J Oral Maxillofac Surg. 2004;33:454-7.
28. Shingaki, Nomura S, Takada T, Kobayashi M, Suzuki T, Nakajima I. Squamous cell carcinomas of the mandibular alveolus: analysis of prognostic factors. Oncology 2002;62(1):17-24. 